\title{
Conventional, Acupuncture-Like or Brief-Intense: Is There Any Difference Between TENS Modalities According to Outcomes of Chronic Low Back Pain with Lumbar Disc Herniation
}

\author{
Ilker Ilhanli \\ Department of Physical Medicine and Rehabilitation, School of Medicine, Giresun University, Giresun, Turkey
}

Email address:

ilkerilhanli@hotmail.com

To cite this article:

Ilker Ilhanli. Conventional, Acupuncture-Like or Brief-Intense: Is There Any Difference Between TENS Modalities According to Outcomes of Chronic Low Back Pain with Lumbar Disc Herniation. Clinical Medicine Research. Vol. 4, No. 5, 2015, pp. 143-150.

doi: $10.11648 /$ j.cmr.20150405.14

\begin{abstract}
Objectives: To evaluate the differences between Conventional, Acupuncture-like and Brief-intense TENS in chronic low back pain with lumbar disc herniation. Methods: 160 patients who were diagnosed as lumbar disc herniation were randomized into 4 groups: Group1= Conventional TENS, Group2= Acupuncture-like TENS, Group3= Brief-intense TENS, Group4= Sham TENS. Hotpack, ultrasound and exercise were applied all groups (5 days/week for 3 weeks). Patients were evaluated before treatment, a week after baseline, at the end of treatment and a month after the end of treatment. Ostwestry Low Back Pain Disability Questionnaire (OLBP) and Short-Form 36 physical component (SF-36PCS), mental component (SF36MCS) scores, Modified Lumbar Schober test (MLS), Straight Leg Raising test (SLR) and Femoral Stretching test (FS) results and Visual Analog Scale for pain (VAS) at activity and at rest were recorded. After the exclusion, statistical analysis was administered to 135 participants (44 males and 91 females). Results: There were no differences according to demographic data $(\mathrm{p}>0,05)$. For each evaluation step, we compared the means of MLS, SLR, VASactivity, VASrest, OLBP, SF-36PCS and SF$36 \mathrm{MCS}$ and found no significant difference $(\mathrm{p}>0,05)$. At the end of first week, all groups showed significant improvement according to SLR ( $\mathrm{p}=0,046, \mathrm{p}=0,035, \mathrm{p}=0,035, \mathrm{p}=0,045$, respectively) and VASrest $(\mathrm{p}=0,038, \mathrm{p}=0,048, \mathrm{p}=0,045, \mathrm{p}=0,048$, respectively); only group $1(\mathrm{p}=0,034)$ and group $3(\mathrm{p}=0,045)$ showed significant improvement for VASactivity. At the end of treatment, all groups showed significant improvement for MLS, SLR, VASactivity, VASrest, OLBP and SF-36PCS ( $<<0,05)$. Conclusions: Pain relief is seem to be starting earlier in treatment regimens including conventional and brief-intense TENS. Probably, final outcomes of the treatment regimens for pain and functional capacity, with or without TENS don't differ.
\end{abstract}

Keywords: TENS, Lumbar Back Pain, Lumbar Disc Herniation

\section{Introduction}

Low back pain (LBP) is very common in the general population, and it's a common cause of disability and work loss [1]. Approximately, $60-80 \%$ of the adults suffer from LBP during their life. Prevalance of lumbar disc herniation $(\mathrm{LDH})$ is nearly $1-3 \%$ of the general population. Basic aims of the treatment in LDH are reducing pain, preventing chronicity and quicken the return to work. For chronic pain, reducing pain and improving the functionality are the main goals of the treatment. Most of the patients benefit from conservative treatment regimens and only $5-10 \%$ of them need surgery. Conservative treatment regimens include; rest, medication, physical therapy (electrotherapy, hotpack, ultrasound, traction, exercise etc.), manuel therapy, spinal orthesis, epidural and paravertebral blokage of neuronal roots. Generally, $50 \%$ of the patients with LDH are recovered by conservative treatment regimens or as a natural consequence [2].

Reducing pain, inflammation, muscular symptomes and joint stiffness are the goals of physical therapy for symptomatic recovery. Also, it is a psychotherapeutic approach by the psychological support, during physiotherapy. Physical therapy contains combinations of different modalities with exercise and education of patients. Electrotherapy provides analgesia and muscle contraction, 
reduces joint stiffness, increases range of motion and muscle strenght and prevents muscle atrophy. It is suggested that, by the electrical currents, A alpha nerve fibers are stimulated, transmission of nociceptive impuls are inhibited and release of the neurotransmitters are increased. Transcutaneous Electrical Nerve Stimulation (TENS) is an electrotherapy method for the inhibition of nociceptors, blockade transmission of pain at afferent nerves, sympathetic blockage and increasing the release of endogenous opioids [3].

Conventional TENS: It is a current with high frequency $(100 \mathrm{~Hz})$ and low amplitude. Duration of the therapy differs (30 minutes to few hours). It is applied at an amplitude which provides paralgesia without muscle contraction. Frequently, accommodation (perceptual-sensory adaptation to TENS) occurs; so the amplitude must be increased step by step. Analgesic effect starts in 10-15 minutes and continues for 10-15 minutes.

Acupuncture-like TENS: It is a current with low frequency $(5 \mathrm{~Hz})$ and high amplitude. Duration of the therapy is $30-60$ minutes. It is applied at an amplitude which provides muscle contraction at a tolerable level for patient. Analgesic effect starts in few hours and continues for 2-6 hours. It is more resistive to accommodation.

Brief- intense TENS: It is a current with high frequency $(150 \mathrm{~Hz})$ and high amplitude. Duration of the therapy is $15-$ 30 minutes. Both the sensory and motor fibers are stimulated. It is applied at an amplitude which provides irregular, tetanic muscle contraction. Analgesic effect starts in 1-15 minutes and disappears quickly.

Randomized studies evaluating the effectiveness of the modalities of physical therapy for LBP are limited and there is shortage and controversy of evidence based data. The aim of this study was to evaluate the differences between TENS modalities (Conventional, Acupuncture-like and Briefintense TENS vs. sham TENS) in chronic LBP with LDH.

\section{Materials and Methods}

A hundred and sixty patients with LBP (more than 3 months, 52 males and 108 females) who were diagnosed as LDH with magnetic resonance imaging (MRI) were included in the study. Accordance with the requirements of ethical standards (Helsinki Declaration), written consents of all patients were obtained, and patients were randomized into 4 groups by computer.

Conventional TENS (30 minutes), hotpack (30 minutes), ultrasound ( 5 minutes, continuous mode- $1.5 \mathrm{watt} / \mathrm{cm}^{2}$ ) and isometric flexion, extension and stretching exercises were applied to first group (13 males and 27 females, 5 days/week for 3 weeks).

Acupuncture-like TENS (30 minutes), hotpack (30 minutes), ultrasound (5 minutes, continuous mode-1.5 watt $/ \mathrm{cm}^{2}$ ) and isometric flexion, extension and stretching exercises were applied to second group (13 males and 27 females, 5 days/week for 3 weeks).

Brief-intense TENS (30 minutes), hotpack (30 minutes), ultrasound (5 minutes, continuous mode- $1.5 \mathrm{watt} / \mathrm{cm}^{2}$ ) and isometric flexion, extension and stretching exercises were applied to third group (13 males and 27 females, 5 days/week for 3 weeks).

Sham TENS (30 minutes, turn-off in $<60$ seconds, electrodes were attached with no current generation), hotpack (30 minutes), ultrasound (5 minutes, continuous mode-1.5 watt $/ \mathrm{cm}^{2}$ ) and isometric flexion, extension and stretching exercises were applied to fourth group (13 males and 27 females, 5 days/week for 3 weeks).

Patients were evaluated before the treatment (Baseline), a week after the beginning of treatment (Second evaluation step), at the end of treatment (Third evaluation step, at $4^{\text {th }}$ week) and a month after the end of treatment (Fourth evaluation step, at $8^{\text {th }}$ week). Instead of demonstrating the cumulative effects of TENS or effects of long term usage, these evaluation steps were choosen according to literature, to demonstrate the effects while the TENS is used and after a designated period of use [3]. Demographic data (age, gender, occupation, body mass index, duration of complaints) was obtained. Ostwestry Low Back Pain Disability Questionnaire (OLBP) and Short-Form 36 (SF-36) questionnaire were applied at each evaluation step. Questionnaires were fulfilled by the patients and delivered to investigator after fourth evaluation step. All physical examinations were done by the same physician (NG) who was blind for treatment groups. Modified Lumbar Schober test (MLS), Straight Leg Raising test (SLR) and Femoral Stretching test (FS) results and Visual Analog Scale for pain (VAS) at activity and at rest were recorded at each evaluation step. Also, examination for sensation and reflex was included.

Ostwestry Low Back Pain Disability Questionnaire (OLBP) is a 10-itemed questionnaire that assesses health status of patients with LBP [4]. Cultural adaptation and validation of this instrument was studied and it was found comprehensible, valid and useful in Turkish patients with LBP [5]. A higher score between 0 and 100, indicates higher disability.

Short Form-36 (SF-36) is a generic outcome measure, evaluating physical and mental function with Physical Component Score (PCS) and Mental Component Score (MCS) [6]. Validity of the Turkish version of SF-36 was studied and was found valid [7]. A higher score indicates better health.

Modified Lumbar Schober test (MLS) is a method for measuring the flexion capability of lumbar region. Limitation of the lumbar flexion and pain, generally shows the discopathy. Femoral Stretching test (FS) evaluates the discopathies which irritates the roots (L2-L4), composing femoral nerve. Straight Leg Raising test (SLR) is a sensitive test which evaluates the irritation of sciatic nerve and by the existence of affected roots (L4,L5,S1,S2,S3) composing sciatic nerve, test is positive [8]. Visual Analog Scale (VAS) for pain (0 to 10$)$ is used to assess the severity of pain and 10 indicates the worst pain.

In case of need, patients were allowed to use maximum 2 grams acetaminophen (a pill $=500$ milligrams) and recording the amount of usage (pills per day) was requested. Patients 
were warned for not using painkiller from 24 hours before control, till the physical examination. By the reason of providing a standardization, patients who were co-medicated with nonsteroidal antiinflamatory drugs, antidepressants or opioids were excluded from the study. Patients who were suffering from pain at another body region, except LBP, and patients who were treated with physical therapy before, for any region of body, were not included in the study for the same reason. By this way, we tried to provide homogeneous groups and prevent the bias for treatment, especially for the sham TENS. Patients who didn't complete all questionnaires or the treatment and who didn't come to control, were excluded from the study. We also considered avoiding possible communications among the patients from different groups to prevent the bias for treatment regimens.

\section{Statistical Analysis}

Statistical analysis were performed with SPSS 16.0. For comparing the variables providing the assumption of normality in independent groups $t$ test was used and for variables not providing the assumption of normality Mann Whitney $U$ test was used. For categorical variables chi square test was used. For repeated measures, in case of providing the assumption of normality, Repeated-measures ANOVA was used and in case of not providing the assumption of normality, difference between treatment groups was tested with nonparametric Friedman test. To determine in which evaluation step the differences were occurred, nonparametric Benferroni-corrected Wilcoxon signed rank test was used. $\mathrm{P}<0,05$ was considered statistically significant.

\section{Results}

A hundred and sixty patients with chronic LBP (52 males and 108 females), who were diagnosed as LDH were included in the study. Patients were randomized into 4 groups, 13 males and 27 females for each:

Group $1=$ Conventional TENS + Hotpack + Ultrasound + Exercise,

Group 2= Acupuncture-like TENS + Hotpack + Ultrasound + Exercise,

Group 3= Brief-intense TENS + Hotpack + Ultrasound + Exercise,

Group 4= Sham TENS + Hotpack + Ultrasound + Exercise

After the exclusion of the patients who didn't complete the whole questionnaires or the treatment or co-medicated with nonsteroidal antiinflamatory drugs, antidepressants or opioids, statistical analysis was administered to 135 participants (44 males and 91 females). See Trial profile flow chart in Figure 1. Excluded patients due to co-medication were as below:

Group 1: 4 patients co-medicated with nonsteroidal antiinflamatory drug;

Group 2: 2 patients co-medicated with nonsteroidal antiinflamatory drug;

Group 3: 3 patients co-medicated with nonsteroidal antiinflamatory drug, 1 patient co-medicated with antidepressant;

Group 4: 4 patients co-medicated with non-steroidal antiinflamatory drug, 3 patients co-medicated with antidepressant..

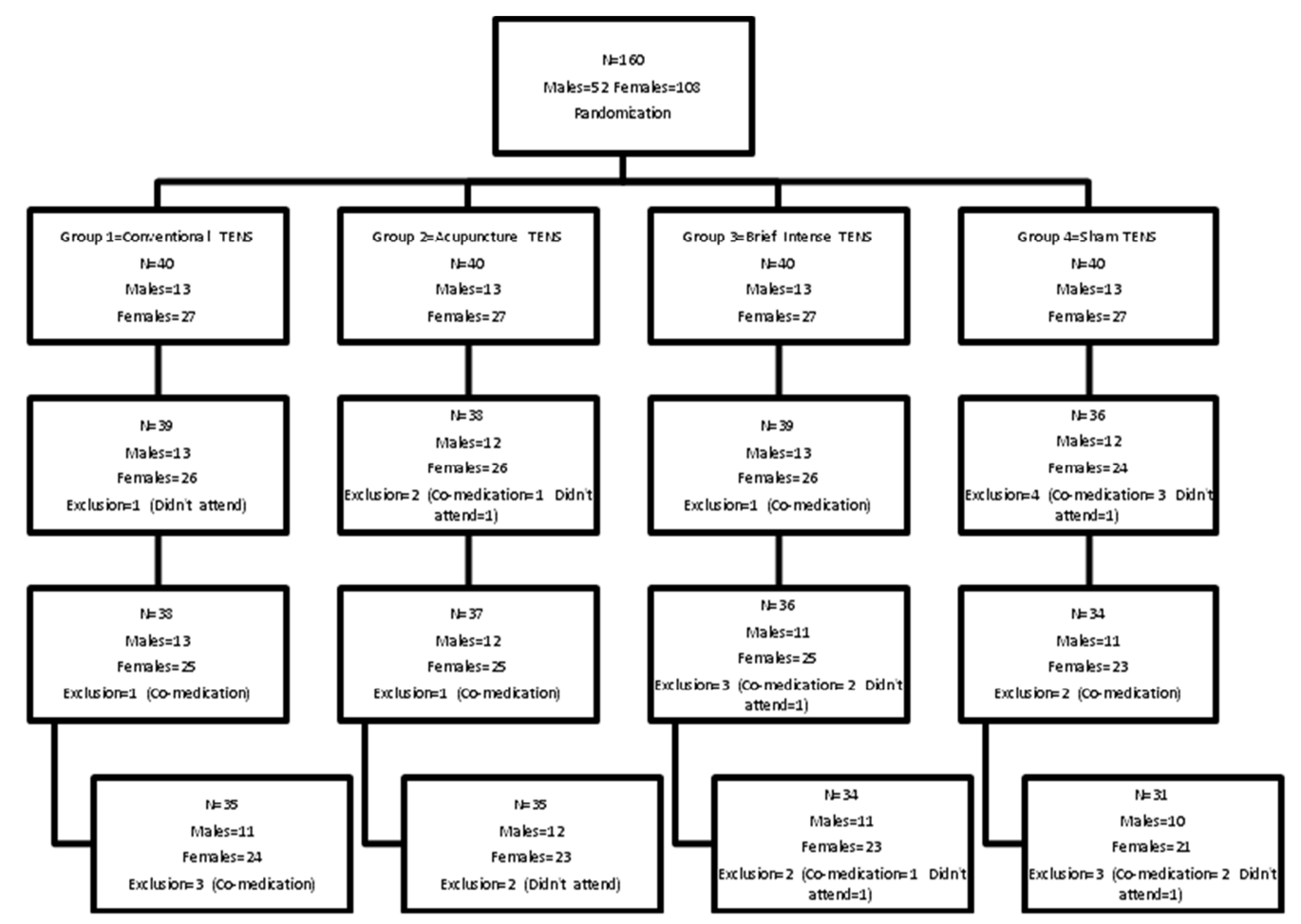

Figure 1. Trial profile flow chart. 
There were no differences among groups according to age, gender, body mass index and duration of complaints ( $p>0,05$, Table 1). There was no difference among groups according to percents of occupation (For all groups approximatelly; 37\% white collar, $33 \%$ blue collar, $7 \%$ retired, $23 \%$ house wife; $\mathrm{p}=0,155)$. Most of the patients were diagnosed as protrusion and there was no difference among groups according to findings in MRI (For all groups approximatelly; 91\% protrusion and $9 \%$ extrusion, $\mathrm{p}=0,084,83 \%$ with spondylosis and $7 \%$ without spondylosis, $p=0,348$ ). There were no differences among groups according to the level of $\mathrm{LDH}$ (For all groups approximatelly; 2\% L3-4, 38\% L4-5, 57\% L5-S1, 2\% L4-5+L5-S1, 1\% L3-4+L4-5+L5-S1, p=0,932). According to loss of sensation there was no difference among groups (For all groups approximatelly; 3\% sensation loss and $97 \%$ normal, $\mathrm{p}=0,573$ ). In any patient, there was no decrease or loss of reflex and muscle strenght. We didn't find positive FS, in any of the patients, too. According to usage of painkiller, there was no significant difference among groups (Group 1: 1,74 $\pm 0,72$ pills/day, Group 2: 1,58 $\pm 0,65$ pills/day, Group 3: $1,62 \pm 0,68$ pills/day, Group 4: $1,78 \pm 0,71$ pills/day; $\mathrm{p}=0,567)$.

There were no adverse events due to treatment regimens. For each evaluation step, we compared the means of MLS, SLR, VASactivity, VASrest, OLBP, SF-36 PCS and SF-36 MCS and found no significant difference among groups ( $p>0,05$, Table 2).

Table 1. Comparison of the demographic variables $(N=135)$.

\begin{tabular}{|c|c|c|c|c|c|}
\hline & Group $1(\mathrm{~N}=35)$ & Group $2(N=35)$ & Group $3(N=34)$ & Group $4(N=31)$ & $P$ value \\
\hline Gender $(\%$, male $)$ & 31,43 & 34,29 & 32,35 & 32,25 & 0,373 \\
\hline Age (years, mean $\pm \mathrm{SD}$ ) & $57,13 \pm 15,86$ & $58,19 \pm 16,18$ & $55,86 \pm 15,86$ & $57,05 \pm 15,46$ & 0,402 \\
\hline BMI $\left(\mathrm{Kg} / \mathrm{m}^{2}\right.$, mean $\left.\pm \mathrm{SD}\right)$ & $25,44 \pm 4,66$ & $26,36 \pm 4,17$ & $25,84 \pm 4,36$ & $26,34 \pm 4,16$ & 0,651 \\
\hline Duration of complaints (months, mean $\pm \mathrm{SD}$ ) & $36,53 \pm 22,23$ & $38,48 \pm 24,31$ & $37,45 \pm 23,42$ & $36,75 \pm 21,83$ & 0,160 \\
\hline
\end{tabular}

*Significance level: p<0,05, BMI: body mass index, SD: standard deviation, Kg: kilogram, m: meter

Table 2. Comparison of groups for each evaluation step $(N=135)$.

\begin{tabular}{|c|c|c|c|c|c|c|}
\hline & Evaluation Step & $\begin{array}{l}\text { Group } 1 \text { (Mean } \pm \text { SD, } \\
\mathbf{N}=35)\end{array}$ & $\begin{array}{l}\text { Group } 2(\text { Mean } \pm \text { SD, } \\
\mathrm{N}=35)\end{array}$ & $\begin{array}{l}\text { Group } 3 \text { (Mean } \pm \text { SD, } \\
\mathbf{N}=34)\end{array}$ & $\begin{array}{l}\text { Group } 4(\text { Mean } \pm \text { SD, } \\
\mathrm{N}=31)\end{array}$ & P value \\
\hline \multirow[t]{4}{*}{ MLS(cm) } & 1 & $5,33 \pm 1,50$ & $5,98 \pm 1,15$ & $5,43 \pm 1,63$ & $5,37 \pm 1,56$ & 0,066 \\
\hline & 2 & $5,78 \pm 1,49$ & $6,35 \pm 1,15$ & $5,88 \pm 1,59$ & $5,82 \pm 1,52$ & 0,100 \\
\hline & 3 & $6,24 \pm 1,15$ & $6,50 \pm 2,90$ & $6,40 \pm 2,05$ & $6,35 \pm 1,90$ & 0,673 \\
\hline & 4 & $6,50 \pm 1,90$ & $6,55 \pm 2,65$ & $6,52 \pm 2,55$ & $6,51 \pm 2,76$ & 0,880 \\
\hline \multirow[t]{4}{*}{ SLR(degree) } & 1 & $59,00 \pm 16,00$ & $60,00 \pm 14,50$ & $59,50 \pm 16,50$ & $59,50 \pm 16,00$ & 0,817 \\
\hline & 2 & $69,67 \pm 15,56$ & $73,39 \pm 11,21$ & $71,35 \pm 11,02$ & $69,17 \pm 15,40$ & 0,336 \\
\hline & 3 & $75,38 \pm 10,19$ & $76,11 \pm 8,92$ & $75,51 \pm 7,92$ & $75,58 \pm 11,09$ & 0,886 \\
\hline & 4 & $76,11 \pm 8,92$ & $76,81 \pm 9,42$ & $76,22 \pm 8,85$ & $76,13 \pm 8,78$ & 0,890 \\
\hline \multirow[t]{4}{*}{ VASactivity } & 1 & $5,18 \pm 1,33$ & $5,27 \pm 1,43$ & $6,05 \pm 1,23$ & $5,90 \pm 1,36$ & 0,346 \\
\hline & 2 & $4,75 \pm 1,35$ & $5,22 \pm 1,34$ & $5,48 \pm 1,35$ & $5,87 \pm 1,53$ & 0,815 \\
\hline & 3 & $3,55 \pm 1,34$ & $3,65 \pm 1,31$ & $3,76 \pm 1,30$ & $3,89 \pm 1,32$ & 0,425 \\
\hline & 4 & $2,44 \pm 1,14$ & $2,43 \pm 1,21$ & $2,55 \pm 1,19$ & $2,97 \pm 1,22$ & 0,877 \\
\hline \multirow[t]{3}{*}{ VASrest } & 1 & $3,45 \pm 1,11$ & $3,56 \pm 1,09$ & $3,35 \pm 1,14$ & $3,49 \pm 1,12$ & 0,592 \\
\hline & 2 & $3,14 \pm 1,04$ & $3,43 \pm 1,10$ & $3,19 \pm 1,01$ & $3,35 \pm 1,07$ & 0,879 \\
\hline & 4 & $2,04 \pm 1,15$ & $1,45 \pm 1,10$ & $2,25 \pm 1,11$ & $2,33 \pm 1,12$ & 0,344 \\
\hline \multirow[t]{4}{*}{ Ostwestry } & 1 & $50,68 \pm 12,43$ & $49,88 \pm 13,41$ & $51,76 \pm 11,55$ & $50,95 \pm 13,05$ & 0,660 \\
\hline & 2 & $49,85 \pm 13,11$ & $48,72 \pm 18,12$ & $50,92 \pm 12,85$ & $50,65 \pm 12,13$ & 0,126 \\
\hline & 3 & $38,75 \pm 17,15$ & $38,47 \pm 17,38$ & $40,54 \pm 11,12$ & $39,95 \pm 12,61$ & 0,416 \\
\hline & 4 & $37,37 \pm 16,55$ & $36,51 \pm 16,48$ & $38,85 \pm 13,62$ & $38,75 \pm 13,45$ & 0,550 \\
\hline \multirow[t]{4}{*}{ SF36 PCS } & 1 & $48,47 \pm 18,28$ & $49,76 \pm 20,33$ & $50,16 \pm 17,95$ & $48,75 \pm 18,15$ & 0,983 \\
\hline & 2 & $49,95 \pm 15,43$ & $50,97 \pm 15,08$ & $51,78 \pm 14,57$ & $49,70 \pm 14,46$ & 0,603 \\
\hline & 3 & $64,11 \pm 18,04$ & $62,51 \pm 18,60$ & $63,70 \pm 18,81$ & $60,74 \pm 18,63$ & 0,781 \\
\hline & 4 & $66,49 \pm 16,81$ & $64,27 \pm 16,35$ & $65,45 \pm 16,02$ & $62,73 \pm 16,44$ & 0,759 \\
\hline \multirow[t]{4}{*}{ SF36 MCS } & 1 & $57,33 \pm 18,68$ & $57,68 \pm 18,91$ & $56,75 \pm 19,65$ & $54,45 \pm 19,40$ & 0,653 \\
\hline & 2 & $59,05 \pm 17,15$ & $58,50 \pm 17,45$ & $58,71 \pm 18,63$ & $56,30 \pm 17,55$ & 0,768 \\
\hline & 3 & $62,70 \pm 18,71$ & $61,60 \pm 18,54$ & $61,42 \pm 18,54$ & $59,75 \pm 18,75$ & 0,461 \\
\hline & 4 & $63,55 \pm 17,75$ & $62,55 \pm 17,31$ & $62,50 \pm 17,44$ & $60,76 \pm 17,55$ & 0,562 \\
\hline
\end{tabular}

*Significance level: $\mathrm{p}<0,05$, Group 1: Conventional TENS group, Group 2: Acupuncture TENS group, Group 3: Brief intense TENS group, Group 4: Sham TENS group, 1: Before treatment, 2: A week after administration, 3: At the end of treatment (4th week), 4: A month after the end of treatment (8th week), SD: standard deviation, cm: centimeter, MLS: modified lumbar schober, SLR: straight leg rising test, VAS: Visual analog scale, Ostwestry: Ostwestry low back pain score, SF36 PCS: physical component score of short form 36, SF36 MCS: mental component score of short form 36 
Table 3. Comparison of evaluation steps for each variable in all groups ( $N=135)$.

\begin{tabular}{|c|c|c|c|c|c|c|c|c|}
\hline & $\begin{array}{l}\text { Comparison of } \\
\text { Evaluation steps }\end{array}$ & $\begin{array}{l}\text { MLS } \\
\text { p value }\end{array}$ & $\begin{array}{l}\text { SLR } \\
\text { p value }\end{array}$ & $\begin{array}{l}\text { VAS activity } \\
\text { p value }\end{array}$ & $\begin{array}{l}\text { VAS rest } \\
\text { p value }\end{array}$ & $\begin{array}{l}\text { Ostwestry } \\
\text { p value }\end{array}$ & $\begin{array}{l}\text { SF36 PCS } \\
\text { p value }\end{array}$ & $\begin{array}{l}\text { SF36 MCS } \\
\text { p value }\end{array}$ \\
\hline \multirow{6}{*}{ Group 1} & $1-2$ & 0,985 & $0,046^{*}$ & $0,034^{*}$ & $0,038^{*}$ & 0,940 & 0,925 & 0,856 \\
\hline & $1-3$ & $0,025^{*}$ & $0,000^{*}$ & $0,020^{*}$ & $0,020^{*}$ & $0,001^{*}$ & $0,005^{*}$ & 0,445 \\
\hline & $1-4$ & $0,005^{*}$ & $0,000^{*}$ & $0,001^{*}$ & $0,004^{*}$ & $0,000^{*}$ & $0,001^{*}$ & 0,536 \\
\hline & $2-3$ & $0,020^{*}$ & $0,024^{*}$ & $0,008^{*}$ & $0,045^{*}$ & $0,005^{*}$ & $0,005^{*}$ & 0,480 \\
\hline & $2-4$ & $0,015^{*}$ & $0,036^{*}$ & $0,005^{*}$ & $0,048^{*}$ & $0,001^{*}$ & $0,001^{*}$ & 0,435 \\
\hline & $3-4$ & 0,256 & 0,357 & $0,048^{*}$ & 0,109 & 0,536 & 0,165 & 0,162 \\
\hline \multirow{6}{*}{ Group 2} & $1-2$ & 0,885 & $0,035^{*}$ & 0,054 & $0,048^{*}$ & 0,845 & 0,836 & 0,757 \\
\hline & $1-3$ & $0,035^{*}$ & $0,00 I^{*}$ & $0,028^{*}$ & $0,010^{*}$ & $0,001^{*}$ & $0,025^{*}$ & 0,356 \\
\hline & $1-4$ & $0,015^{*}$ & $0,000^{*}$ & $0,015^{*}$ & $0,005^{*}$ & $0,000^{*}$ & $0,005^{*}$ & 0,444 \\
\hline & $2-3$ & $0,025^{*}$ & $0,025^{*}$ & $0,025^{*}$ & $0,035^{*}$ & $0,005^{*}$ & $0,025^{*}$ & 0,525 \\
\hline & $2-4$ & $0,020^{*}$ & $0,045^{*}$ & $0,015^{*}$ & $0,045^{*}$ & $0,001^{*}$ & $0,010^{*}$ & 0,516 \\
\hline & $3-4$ & 0,358 & 0,256 & $0,005^{*}$ & $0,019^{*}$ & 0,446 & 0,255 & 0,260 \\
\hline \multirow{6}{*}{ Group 3} & $1-2$ & 0,775 & $0,035^{*}$ & $0,045^{*}$ & $0,045^{*}$ & 0,345 & 0,536 & 0,540 \\
\hline & $1-3$ & $0,045^{*}$ & $0,001^{*}$ & $0,010^{*}$ & $0,010^{*}$ & $0,025^{*}$ & $0,035^{*}$ & 0,245 \\
\hline & $1-4$ & $0,025^{*}$ & $0,000^{*}$ & $0,015^{*}$ & $0,005^{*}$ & $0,010^{*}$ & $0,015^{*}$ & 0,350 \\
\hline & $2-3$ & $0,035^{*}$ & $0,025^{*}$ & $0,025^{*}$ & $0,035^{*}$ & $0,015^{*}$ & $0,036^{*}$ & 0,460 \\
\hline & $2-4$ & $0,032^{*}$ & $0,036^{*}$ & $0,005^{*}$ & $0,045^{*}$ & $0,020^{*}$ & $0,025^{*}$ & 0,425 \\
\hline & $3-4$ & 0,457 & 0,256 & $0,035^{*}$ & 0,125 & 0,646 & 0,360 & 0,275 \\
\hline \multirow{6}{*}{ Group 4} & $1-2$ & 0,435 & $0,045^{*}$ & 0,070 & $0,048^{*}$ & 0,555 & 0,646 & 0,630 \\
\hline & $1-3$ & $0,042^{*}$ & $0,005^{*}$ & $0,015^{*}$ & $0,015^{*}$ & $0,036^{*}$ & $0,038^{*}$ & 0,345 \\
\hline & $1-4$ & $0,023^{*}$ & $0,001^{*}$ & $0,020^{*}$ & $0,012^{*}$ & $0,015^{*}$ & $0,008^{*}$ & 0,355 \\
\hline & $2-3$ & $0,040^{*}$ & $0,015^{*}$ & $0,030^{*}$ & $0,040^{*}$ & $0,026^{*}$ & $0,026^{*}$ & 0,430 \\
\hline & $2-4$ & $0,026^{*}$ & $0,045^{*}$ & $0,015^{*}$ & $0,045^{*}$ & $0,035^{*}$ & $0,025^{*}$ & 0,475 \\
\hline & $3-4$ & 0,325 & 0,245 & $0,045^{*}$ & 0,425 & 0,840 & 0,460 & 0,365 \\
\hline
\end{tabular}

"Significance level: $\mathrm{p}<0,05$, Group 1: Conventional TENS group, Group 2: Acupuncture TENS group, Group 3: Brief intense TENS group, Group 4: Sham TENS group, 1: Before treatment, 2: A week after administration, 3: At the end of treatment (4th week), 4: A month after the end of treatment (8th week), SD: standard deviation, cm: centimeter, MLS: modified lumbar schober, SLR: straight leg rising test, VAS: Visual analog scale, Ostwestry: Ostwestry low back pain score, SF36 PCS: physical component score of short form 36, SF36 MCS: mental component score of short form 36

At the end of first week, all groups showed significant improvement according to SLR ( $\mathrm{p}=0,046, \mathrm{p}=0,035, \mathrm{p}=0,035$, $\mathrm{p}=0,045$, respectively) and VASrest $(\mathrm{p}=0,038, \mathrm{p}=0,048$, $\mathrm{p}=0,045, \mathrm{p}=0,048$, respectively) . According to VASactivity, only group $1(\mathrm{p}=0,034)$ and group $3(\mathrm{p}=0,045)$ showed significant improvement at first week. According to other parameters, we found no significant improvement in any of the groups $(\mathrm{p}<0,05)$.

At the end of treatment, all groups showed significant improvement for MLS, SLR, VASactivity, VASrest, OLBP and SF-36 PCS $(\mathrm{p}<0,05)$. In any group, we found no significant change for SF-36 MCS ( $p>0,05)$. A month after the end of treatment, all groups showed a significant, continuing improvement for VASactivity ( $\mathrm{p}=0,048, \mathrm{p}=0,005$, $\mathrm{p}=0,035, \mathrm{p}=0,045$, respectively), but only group 2 showed a significant, continuing improvement for VASrest $(\mathrm{p}=0,019)$, together with VASactivity (Table 3 ).

\section{Discussion}

Despite the high frequency of LBP, incidence of LDH is less than the expected. Because of high costs, LBP is emerging as a common socioeconomic and sociomedical problem. Currently, there isn't a consensus on a standardized treatment modality $[9,10]$. Transcutaneous electrical nerve stimulation (TENS) is an electrotherapeutic procedure used for pain control that has been examined in the medical literature since its introduction by Wall and Sweet in 1967 [11]. It is suggested that TENS usage reduces the costs and going surgery, so the studies should be expanded and diversified in this field [12].

There are some limitations in this study. Drop out rate of this study was approximately $16 \%$ of total subject number. Although, most of them was from group 4, all groups were similar according to demographic variables. Subject number should be more, but as we know, it's hard to find patients with no experience of physical therapy. We demanded this requirement for preventing the bias for treatment modalities, especially for sham TENS. Combined treatment modalities inconvenience to comment on the effectiveness of each component [13]. Studying treatment modalities alone is more effective than studying the combination of them, but a sham treatment modality without combination isn't ethical. So, we combined the TENS modalities with other physical therapy methods (heaters and exercise), which are known as effective. We allowed patients to take medication, but for providing a standardization as far as possible, patients with comedication (nonsteroidal antiinflammatory drugs, antidepressants, opioids etc.) were excluded, except acetaminophen- first choose in LBP [14]. Amount of the taken pills were recorded to evaluate the approximate effect of treatment regimens on pain relief, but the response of 
patients to painkillers or treatment regimens or standardizing the amounts of taken painkillers in each group is out of control. Exclusion rate due to co-medication was higher in sham TENS group than the others, which may be casualness or may show the analgesic effect of TENS. Also, comedication with antidepressants was higher in sham TENS group (3 patients co-medicated with antidepressant), which increases the number of exclusion. Although we found no significant difference among groups according to mental health measured with SF-36 MCS, relatively mean of SF-36 MCS was lower in group 4 (Table 2) than the other groups and this could be the main reason of higher number of antidepressant usage. However, we should keep in mind that recent evidence has highlighted the role of psychological and psychosocial factors in the aetiology of low back pain [1517]. In all groups, there was numerically improvement for SF-36 MCS, but the differences were small and insignificant. Numerically, mean of the taken acetaminophen pills was higher in group 4, but there wasn't a statistically significant difference among groups, which may show that all treatment regimens were similar according to outcomes for pain relief. Follow-up period of patients after treatment was limited to a month to avoid the drop out as far as possible, but for measuring the long term outcomes of the treatment regimens follow-up period should be extended.

Improvement for MLS, SLR, OLBP, SF-36 PCS and VASrest were similar in all groups and at all evaluation steps. In group 2 and 4, improvement for VASactivity was started from the second week of the treatment. There was significant improvement for pain and functional capacity, by the end of treatment in all groups, even in sham TENS group. This situation may show that, either with TENS or not, all treatment modalities are effective in chronic LBP with LDH. Similar to our study, some studies investigating the effectiveness of TENS by comparing with sham didn't find significant difference at short term follow-up [18,19]. However, a study demonstrated a significant carryover effect with conventional TENS having a greater effect on pain intensity than sham TENS [20]. In some studies investigating the effect of TENS on pain relief in patients with disc disease in lumbosacral spine reported TENS therapy as contributing to pain relief and improvement of function and mobility of the lumbosacral spine [21,22].

Stimulation amplitude must be of sufficient level to produce analgesia $[23,24]$. TENS applied at a strong but comfortable intensity provides a significant analgesia [24]. Thus, amplitude must be increased to an adequate level to produce analgesia. Although typically high-frequency TENS is applied to produce a nonpainful paresthesia and lowfrequency TENS is typically applied at higher intensities that produce motor contractions, we encouraged all the patients to continue to increase intensity as tolerated.

We know that exercise is an effective component for pyhsical therapy [25-27], and dynamic lumbar stabilization exercises provide a physiologic bracing in neutral position and quicken the return to work in patients with LDH. Similar to our findings, a systematic review of the literature didn't report significant difference in effect between exercise therapy compared to TENS on the outcomes pain and functionality at short term follow-up [28].

Superficial heater methods can be useful for pain relief and spasm relaxation. Also we know that, deep heater methods like ultrasound, short wave diathermy and microwave diathermy seem to be useful for their physiological effects in pain [28, 29]. Generally, 50\% of the patients with $\mathrm{LDH}$ are recovered by conservative treatment regimens or as a natural consequence [2]. In chronic LBP with $\mathrm{LDH}$, treatment regimens may accelerate and conribute this natural consequence.

Evaluating the functional capacity is an important component for intending the treatment in patients with LBP, because functional disability is common in patients with LBP and different from other clinical syndromes [30]. That's why, a domain specific instrument; OLBP and a general instrument for quality of life; SF-36 were used to evaluate the functional capacity of the patients in this study. Both instruments showed the improvement in functional capacity by the treatment regimens, numerically and statistically.

At the first week of treatment we found no siginificant improvement for VASactivity in acupuncture-like TENS group and sham TENS group, but at following evaluation steps all groups showed significant and similar improvement for VASactivity. Also, as well as VASactivity, acupuncturelike TENS group showed significant ongoing improvement for VASrest between the third and fourth evaluation steps. Maybe, effect of acupuncture-like TENS on pain starts later than other TENS modalities and in a long term follow-up, acupuncture-like TENS could be more effective on pain relief. Having differences wouldn't be surprising, because the analgesic mecanisms of TENS' with lower and higher frequencies are different [3]. Low-frequency TENS (1-10 $\mathrm{Hz})$, like acupuncture-like TENS, activates mu-opioid receptors, and high-frequency TENS (50-150 Hz), like conventional or brief-intense TENS, activates delta-opioid receptors [31,32]. Although TENS may have an effect on resting pain in some populations $[33,34]$, it appears to be more effective for reducing pain during movement and hyperalgesia [35-39]. In our study, both VASactivity and VASrest showed significant improvement by the treatment regimens.

\section{Conclusions}

Pain relief is seem to be starting earlier in treatment regimens including conventional and brief-intense TENS. Probably, final outcomes of the treatment regimens for pain and functional capacity, with or without TENS don't differ. Acupuncture-like TENS may have long term effects on pain relief. Follow-up period and subject number should be increased in further studies.

\section{Abbrevations}

TENS (Transcutaneous Electrical Nerve Stimulation); 
OLBP (Ostwestry Low Back Pain Disability Questionnaire); SF-36 PCS (Short-Form 36 physical component score); SF36 MCS (Short-Form 36 mental component score); MLS (Modified Lumbar Schober test); SLR (Straight Leg Raising test); FS (Femoral Stretching test); VAS (Visual Analog Scale for pain)

\section{Acknowledgments}

Special thanks to Murat Gul (Statistician) and Necip Guder (MD) for their supports.

\section{References}

[1] Andersson GB. Epidemiological features of chronic low-back pain. Lancet 1999;354: 581-585.

[2] Oliphant D. Safety of spinal manipulation in the treatment of lumbar disk herniations: A systematic review and risk assessment. J Manipulative Physiol Therap 2004; 27(3): 197209.

[3] Sluka KA, Bjordal JM, Marchand S, Rakel BA. What Makes Transcutaneous Electrical Nerve Stimulation Work? Making Sense of the Mixed Results in the Clinical Literature. Phys Ther 2013; 93(10): 1397-1402.

[4] Fairbank JC, Couper J, Davies JB, O'Brien JP. The Oswestry Low Back Pain Disability Questionnaire. Physiotherapy 1980; 66: 271-273.

[5] Yakut E, Düger T, Oksüz C, Yörükan S, Ureten K, et al. Validation of the Turkish version of the Oswestry Disability Index for patients with low back pain. Spine (Phila Pa 1976) 2004; 29(5): 581-585.

[6] Ware JE, Sherbourne CD. The SF-36 health status survey: 1. Conceptual framework and item selection. Med Care 1992; 30: 473-483.

[7] Kocyigit H, Aydemir O, Fisek G, Olmez N, Memis A. Kısa form-36'nın Türkce versiyonunun güvenilirliği ve gecerliliği. Ilaç ve Tedavi 1999; 12(2): 102-106.

[8] Vroomen PC, de Krom MC, Wilmink JT, Kester AD, Knottnerus JA. Diagnostic value of history and physical examination in patients suspected of lumbosacral nerve root compression. J Neurol Neurosurg Psychiatry 2002; 72(5): 630-634.

[9] Van Tulder MW, Koes BW, Boster LM. Conservative treatment of acute and chronic nonspecific low back pain: a systematic review of randomized controlled trials of the most common intervention. Spine 1997; 22(18): 2128-2156.

[10] Rantanen P. Physical measurements and questionnaires as diagnostic tools in chronic low back pain. J Rehabil Med 2001; 33(1): 31-35.

[11] Wall PD, Sweet WH. Temporary abolition of pain in man. Science 1967; 155: 108-109.

[12] Pivec R, Stokes M, Chitnis AS, Paulino CB, Harwin SF, Mont MA. Clinical and economic impact of TENS in patients with chronic low back pain: analysis of a nationwide database. Orthopedics 2013; 36(12): 922-928.
[13] Rattanatharn R, Sanjaroensuttikul N, Anadirekkul P, Chaivisate R, Wannasetta W. Effectiveness of lumbar traction with routine conservative treatment in acute herniated disc syndrome. J Med Assoc Thai 2004; 87(2): 272-277.

[14] Carette S, Marcoux S, Truchon R, Grondin C, Gagnon J, et al. A controlled trial of corticosteroid injections into facet joints for chronic low back pain. N Engl J Med 1991; 325(14): 1002-1007.

[15] Papageorgiou AC, Macfarlane GJ, Thomas E, Croft PR, Jayson MI, et al. Psychosocial factors in the workplace - do they predict new episodes of low back pain? Evidence from the South Manchester Back Pain Study. Spine 1997; 22: 11371142 .

[16] Harkness EF, Macfarlane GJ, Nahit ES, Silman AJ, McBeth J. Risk factors for new onset low back pain amongst cohorts of newly employed workers. Rheumatology 2003; 42: 959-968.

[17] Jones GT, Watson KD, Silman AJ, Symmons DPM, Macfarlane GJ. Predictors of low back pain in British schoolchildren: a population-based prospective cohort study. Pediatrics 2003; 111: 822-828.

[18] Deyo RA, Walsh NE, Martin DC, Schoenfeld LS, Ramamurthy S. A controlled trial of transcutaneous electrical nerve stimulation (TENS) and exercise for chronic low back pain. N Engl J Med 1990; 322: 1627-1634.

[19] Jarzem PF, Harvey EJ, Arcaro N, Kaczorowski J. Transcutaneous Electrical Nerve Stimulation (TENS) for Chronic Low Back Pain. J Musculoskelet Pain 2005; 13: 3-9.

[20] Jarzem PF, Harvey EJ, Arcaro N, Kaczorowski J. Transcutaneous electrical nerve stimulation (TENS) for shortterm treatment of low back pain-randomized double blind crossover study of sham verus conventional TENS. J Musculoskelet Pain 2005; 13: 11-17.

[21] Pop T, Austrup H, Preuss R, Niedziałek M, Zaniewska A, Sobolewski M, Dobrowolski T, Zwolińska J. Effect of TENS on pain relief in patients with degenerative disc disease in lumbosacral spine. Ortop Traumatol Rehabil 2010; 12(4): 289-300.

[22] Ratajczak B, Hawrylak A, Demidaś A, Kuciel-Lewandowska J, Boerner E. Effectiveness of diadynamic currents and transcutaneous electrical nerve stimulation in disc disease lumbar part of spine. J Back Musculoskelet Rehabil 2011; 24(3): $155-159$.

[23] Rakel B, Cooper N, Adams HJ, Messer BR, Frey Law LA, et al. A new transient sham TENS device allows for investigator blinding while delivering a true placebo treatment. J Pain 2010; 11: 230-238.

[24] Moran F, Leonard T, Hawthorne S, Hughes CM, McCrumGardner E, et al. Hypoalgesia in response to transcutaneous electrical nerve stimulation (TENS) depends on stimulation intensity. J Pain 2011; 12: 929-935.

[25] Koldas Dogan S, Sonel Tur B, Kurtais Y, Atay MB. Comparison of three different approaches in the treatment of chronic low back pain. Clin Rheumatol 2008; 27: 873-881.

[26] Tekur P, Singphow C, Nagendra HR, Raghuram N. Effect of short-term intensive yoga program on pain, functional disability, and spinal flexibility in chronic low back pain: a randomized control study. J Altern Complement Med 2008; 14: 637-644. 
[27] Frost H, Klaber Moffet JA, Moser JS, Fairbank JC. Randomised controlled trial for evaluation of fitness programme for patients with chronic low back pain. BMJ 1995; 310: 151-154.

[28] Middelkoop M, Rubinstein SM, Kuijpers T, Verhagen AP, Ostelo R, Koes BW, Tulder MW. A systematic review on the effectiveness of physical and rehabilitation interventions for chronic non-specific low back pain. Eur Spine J 2011; 20(1): 19-39.

[29] Unlu Z, Tasci S, Tarhan S, Pabuscu Y, Islak S. Comparison of 3 physical therapy modalities for acute pain in lumbar disc herniation measured by clinical evaluation and magnetic resonance imaging. J Manipulative Physiol Ther 2008; 31(3): 191-198.

[30] Rantanen P. Physical measurements and questionnaires as diagnostic tools in chronic low back pain. J Rehabil Med 2001; 33(1): 31-35.

[31] Kalra A, Urban MO, Sluka KA. Blockade of opioid receptors in rostral ventral medulla prevents antihyperalgesia produced by transcutaneous electrical nerve stimulation (TENS). J Pharmacol Exp Ther 2001; 298: 257-263.

[32] Sluka KA, Deacon M, Stibal A, Strissel S, Terpstra A. Spinal blockade of opioid receptors prevents the analgesia produced by TENS in arthritic rats. J Pharmacol Exp Ther 1999; 289: 840-846.

[33] Facci LM, Nowotny JP, Tormen F, Trevisani VFM. Effects of transcutaneous electrical nerve stimulation (TENS) and interferential currents (IFC) in patients with nonspecific chronic low back pain: randomized clinical trial. Sao Paulo Med J 2011; 129: 206-216.

[34] Marchand S, Charest J, Li J, Chenard JR, Lavignolle B, Laurencelle L. Is TENS purely a placebo effect? A controlled study on chronic low back pain. Pain 1993; 54: 99-106.

[35] Rakel B, Frantz R. Effectiveness of transcutaneous electrical nerve stimulation on postoperative pain with movement. J Pain 2003; 4: 455-464.

[36] Law PP, Cheing GL. Optimal stimulation frequency of transcutaneous electrical nerve stimulation on people with knee osteoarthritis. J Rehabil Med 2004; 36: 220-225.

[37] Law PPW, Cheing GLY, Tsui AYY. Does transcutaneous electrical nerve stimulation improve the physical performance of people with knee osteoarthritis? J Clin Rheumatol 2004; 10: 295-299.

[38] Vance CG, Rakel BA, Blodgett NP, DeSantana JM, Amendola A, Zimmerman MB, Walsh DM, Sluka KA. Effects of transcutaneous electrical nerve stimulation on pain, pain sensitivity, and function in people with knee osteoarthritis: a randomized controlled trial. Phys Ther 2012; 92: 898-910.

[39] Cheing GL, Tsui AY, Lo SK, Hui-Chan CW. Optimal stimulation duration of tens in the management of osteoarthritic knee pain. J Rehabil Med 2003; 35: 62-68. 